\section{Trouble building at Harima}

\section{Tokyo}

PLANS to build the world's largest synchrotron in a new 'science city' in western Japan ran into their first problems last week when a group of construction companies were accused of rigging their bids for ground preparations for the project.

The $8-\mathrm{GeV}$ Synchrotron Radiation Facility is being built by the Science and Technology Agency (STA) in the Harima Science Garden City in Hyogo Prefecture west of Osaka. The garden city will form the core of the Nishi-Harima 'Technopolis', one of several technopolises being established by the Ministry of International Trade and Industry (MITI) and local governments to assist the economic revival of Japan's remoter regions (see Nature 329, 478; 1988).

Preparation of the grounds for the 2,000-hectare garden city will be paid for by the Hyogo Prefectural government and is expected to cost $¥ 120,000$ million ( $\$ 850$ million), according to Tohru Amano, director of STA's office for construction of the synchrotron. The synchrotron itself will cost STA about $¥ 100,000$ million (\$715 million), considerably more than

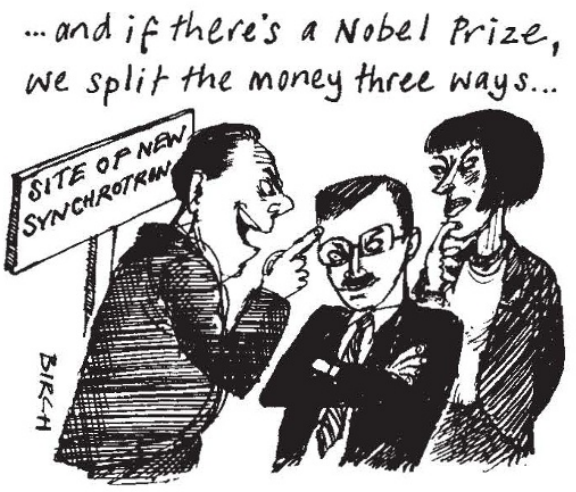

the cost of Japan's present biggest accelerator TRISTAN at the High Energy Physics Laboratory (KEK) of the Ministry of Education, Science and Culture (MESC) in Tsukuba.

Last week's bids were for ground preparations for the 141-hectare site for the synchrotron. The site was divided into two lots for bidding. But on the day before tenders were submitted, an anonymous letter identifying the successful bidders was sent to the Hyogo prefectural government and the mass media. One bid of $¥ 4,270$ million was submitted by Ohbayashi Corporation, Konoike Corporation, Arai-Gumi, Ltd, Konoike Construction Co. and a local company. The other successful bid of $¥ 4,440$ million was made by Nishimatsu Construction Co., Kajima Corporation, Yoshida-Gumi, Ltd, and another local company. These bids were about $¥ 100$ million less than those submitted by nine other groups.
A spokesman for Ohbayashi Corporation was quoted on national television as saying that "there is nothing to indicate that the company was involved in irregular procedures". But Japan's construction industry is notorious for its practice of 'dango', a process whereby big construction companies get together before sub-

\section{Tokyo}

JAPANESE scientists are already lining up in their hundreds to gain access to the 8GeV Synchrotron Radiation Facility even though the synchrotron will not undergo its first trials until 1995 and is not expected to begin full operations until three years after that.

When completed, the Synchrotron Radiation Facility (SOR) will be more powerful than both the 7-GeV Advanced Photon Source (APS) at the Argonnne National Laboratory in the United States, scheduled to be built by 1995 , and the 6-GeV European Synchrotron Radiation Facility (ESRF) at Grenoble, beginning operation in 1993.

According to Amano, about 400 researchers from universities, government and industry have already joined working groups that are now planning use of the synchrotron.

Construction of the facility is being directed by STA's Institute of Physical and Chemical Research (RIKEN) and the Japan Atomic Energy Research Insitute (JAERI), another affiliate of STA. But once completed, the synchrotron will be taken over by a new organization and will be open to use by researchers throughout Japan. Amano says that 'nearby' foreign countries may get access to one or two of the synchrotron's 50 beam lines. Preliminary discussions have been held with researchers from Korea, Taiwan and Australia.

The beams from the synchrotron will be able to resolve features down to the size of an atom, or about one ångström. The facility will be particularly useful for determining the structure of proteins. Japan's present most powerful synchrotron, the Photon Factory at KEK in Tsukuba, a 2.5-GeV facility, takes two to three days to determine the structure of a protein but the same job will take only take two to three minutes at the new facility, according to Amano.

The $8-\mathrm{GeV}$ Synchrotron Radiation Facility is too powerful to use for development of sub-micrometre lithography of VLSI (very-large-scale integration) circuits, a common application for presentday synchrotrons. But Amano says there is plenty of space next to its $1-\mathrm{GeV}$ linear accelerator for smaller synchrotrons that mitting tenders and make a decision about who will win the bid. This is the practice that has been attacked by the United States for effectively shutting foreign companies out of Japan's gigantic construction market.

The Hyogo prefectural government has said that the matter will be thoroughly investigated and Amano is confident that the local government will resolve the situation.

\title{
Hundreds keen to get SOR
}

could be operated by industry, and some companies have shown interest in attaching additional facilities to the synchrotron's linear accelerator. But Sumitomo Heavy Industries and Hitachi have already developed self-contained mini synchrotrons for VLSI development and it is uncertain what role the Synchrotron Radiation Facility will play when it comes into use in eight years' time.

David Swinbanks PRIZES

\section{Japan prize awarded}

\section{Tokyo}

ONE of Japan's most lucrative science prizes, the Japan Prize, has been awarded to Marvin Lee Minsky of MIT in the United States who is credited with developing and popularizing the concept of artificial intelligence. A group of three geologists who helped develop the plate tectonic theory, Dan Mackenzie of Cambridge University in the United Kingdom, Xavier Le Pichon of Ecole Normale Superieure in France and

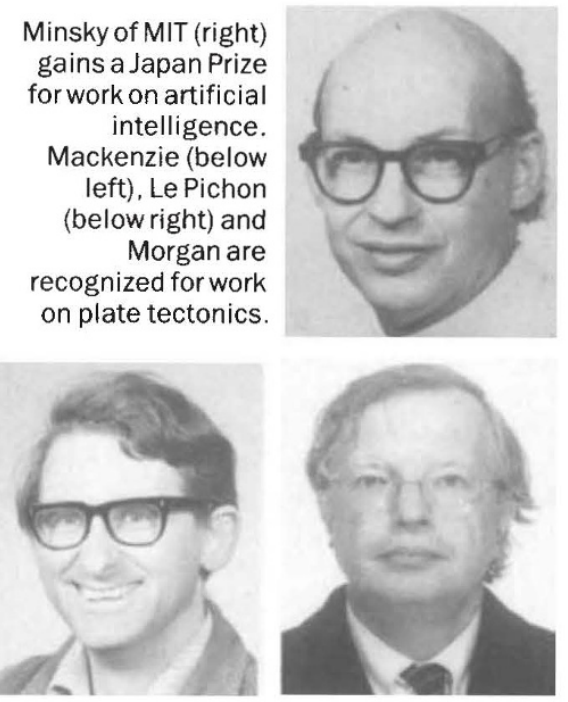

William Jason Morgan of Princeton University, share the other of the two awards announced last week.

The prize is administered by the Science and Technology Foundation of Japan and each award is worth $¥ 50$ million $(\$ 345,000)$. The prizes will be presented in Tokyo on 17 April. David Swinbanks 